The aim of the present study was to compare the effects of selective phosphodiesterase (PDE) 3, 4 and 5 inhibitors on antigen-induced airway hyperresponsiveness in sensitized guinea-pigs. When the sensitized guinea-pigs were orally pre-treated with the selective PDE4 inhibitor, Ro 20-1724 (30 mg/kg), and studied $48 \mathrm{~h}$ after $O A$, a significant reduction $(P<0.01)$ of the leftward $s$ ift of the dose-response curve to ACh was noted, whereas it was ineffective at the lower dose $(10 \mathrm{mg} / \mathrm{kg})$. Administration of the selective PDE3 inhibitor, milrinone $(30 \mathrm{mg} / \mathrm{kg})$ also elicited a significant reduction $(P<0.01)$ of the airway hyperresponsiveness, whereas the PDE5 inhibitor zaprinast $(30 \mathrm{mg} / \mathrm{kg})$ was ineffective. These results show that both PDE3 and PDE4 inhibitors are able to in hibit the antigen-induced airway hyperresponsiveness in sensitized guinea-pigs and support the potential utility of selective PDE inhibitors in the treatment of asth $\mathrm{m}$ a.

Key words: Selective phosphodiesterase inhibitor, Guineapig, Airw ay hyperresponsiveness

\section{Reduced airway hyperresponsiveness by phosphodiesterase 3 and 4 inhibitors in guinea-pigs}

\author{
Noëlla Germain, ${ }^{1}$ Elisabeth Boichot, ${ }^{1}$ \\ Jean-Michel Planquois ${ }^{2}$ and Vincent Lagente ${ }^{1, C A}$
}

${ }^{1}$ INSERM U456, Laboratoire de Pharmacodynamie et de Pharmacologie Moleculaire, Faculte des Sciences Pharmaceutiques et Biologiques, Universite de Rennes 1, 2 Avenue du Pr. Leoon Bernard, 35043 Rennes, France; and ${ }^{2}$ Institut de Recherche Jouveinal/Parke-Davis, Fresnes, France

${ }^{\mathrm{CA}}$ Corresponding Author
Tel.: (+33) 299336850
Fax: (+33) 299336242
Email: vincent.lagente@rennes.inserm.fr

\section{Introduction}

Bronchial asthma is a disease characterized by variable airway obstruction and airway hyperresponsiveness that has been linked to mucosal inflammation and particularly, the influx and activation of eosinophils. ${ }^{1}$ One way to reduce the development of airway hyperresponsiveness is to inhibit the associated inflammation by anti-inflammatory drugs. However, under certain conditions, airw ay hyperresponsiveness has been observed despite the absence of any inflammatory process, such as eosinophil recruitment. We have previously demonstrated that substance $\mathrm{P}$ is able to induce airway hyperresponsiveness not associated with eosinophil recruitment, but with an enhancement of alveolar macrophage activation. ${ }^{2}$

The cyclic nucleotides, cyclic adenosine monophosphate (cyclic AMP) and cyclic guanosine monophosphate (cyclic GMP), are important second messengers of cellular function. Phosphodiesterases (PDEs) are a group of enzymes that regulate the breakdown of cyclic nucleotides. Among PDEs, PDE3 and PDE4 appear to be the most important for the regulation of cyclic AMP, whereas PDE5 is responsible for the level of intracellular cGMP. As far as antiinflammatory drugs are concerned, much attention has been focused on the therapeutic potential of selective PDE4 inhibitors (for review see Refs 3 and 4). It has also been frequently reported that PDE3 inhibitors do not have potent anti-inflammatory effects. This has been clearly demonstrated on eosinophil recruitment induced by antigen challenge, PAF ae rosol ex posure or intratracheal administration of IL-5., ${ }^{5,6}$ This is probably due to the fact that in most inflammatory cells, including eosinophils, the low $\mathrm{K}_{\mathrm{m}}$ cyclic AMP-specific members of the PDE4 family are the most prominently expressed. ${ }^{4,7}$ However, in mononuclear cells, PDE3 is also involved in the regulation of cyclic AMP levels. In macrophages, in the presence of the adenylyl cyclase activator, $\mathrm{PGE}_{2}, \mathrm{PDE} 3$ inhibitors are as effective as PDE4-selective drugs in inhibiting TNF- $\alpha$ release. ${ }^{8}$ We also recently demonstrated that PDE3 and PDE4 isoenzymes are present in alveolar macrophages from sensitized guinea-pigs and that PDE4, but also PDE3, regulate the release of inflammatory mediators. ${ }^{9}$

Numerous studies have reported the actual efficacy of PDE inhibitors, namely selective PDE4 inhibitors, on the development of airway hyperresponsiveness. However the effects of PDE3 inhibitors appear controversial. ${ }^{10-15}$

The present study was undertaken in order to compare the effect of milrinone, a selective PDE3 inhibitor, Ro 20-1724, a selective PDE4 inhibitor, and zaprinast, a selective PDE5 inhibitor, on the development of airw ay hyperresponsiveness in sensitized and challenged guinea-pigs. 


\section{Methods}

\section{Materials}

The following drugs were used : ovalbumin (OA, chicken egg, grade V) and milrinone (Sigma, St. Louis, MO, USA), Ro 20-1724 (RBI, Natick, MA, USA), urethane (ethylcarbamate, Prolabo, Paris, France), pancuronium bromide (Pavulon, Organon, Fresnes, France). Racemic rolipram was synthesized at the Institut de Recherche Jouveinal/Parke-Davis, Fresnes, France. Zaprinast was a generous gift of RhônePoulenc Rorer (UK).

\section{Sensitization procedure and challenge}

Specific pathogen-free male Hartley guinea-pigs (300-350 g, Charles River, St. Aubin les Elboeuf, France) were used throughout the study. Following purchase, they were housed in our standard animal care facilities. All guinea-pigs were fed standard pellet (UAR, Villemoisson-Sur-Orge, France) and given water ad libitum. Guinea-pigs were sensitized and challenged as previously described. ${ }^{16}$ Briefly, they were placed in a Plexiglas chamber $(30 \times 50 \times 30 \mathrm{~cm})$ and exposed twice for $30 \mathrm{~min}$ to an aerosol of ovalbumin (OA) $2 \mathrm{mg} / \mathrm{ml}$ in saline $(\mathrm{NaCl}, 0.9 \%)$, with a $48 \mathrm{~h}$ interval. The aerosol was generated by a Devilbiss ultrasonic nebulizer (Aerodynamic mean mass median particle diameter of 0.5-5 $\mu$ M, ULTRA-NEB 99, Sommerset, PA, USA). Fifteen to 20 days after the initial sensitization procedure, the guinea-pigs were challenged by 15 -min exposures to five successive solutions of $\mathrm{OA}$ of respectively $10 \mu \mathrm{g} / \mathrm{ml}, 100 \mu \mathrm{g} / \mathrm{ml}$, $1 \mathrm{mg} / \mathrm{ml}, 5 \mathrm{mg} / \mathrm{ml}$ and $10 \mathrm{mg} / \mathrm{ml}$. Control guinea-pigs were exposed to a saline solution for an equivalent period of time.

\section{Assessment of airway hyperresponsiveness}

Bronchopulmonary reactivity to acetylcholine was assessed $48 \mathrm{~h}$ after antigen challenge or saline exposure. Guinea-pigs are anaesthetized (urethane, $1.2 \mathrm{~g} / \mathrm{kg}$, i.p.) and placed in a dorsal recumbent position. A trachea cannula was inserted and the lungs were mechanically ventilated with a constant tidal volume ( $1 \mathrm{ml}$ laboratory air/100 g body weight) with a respiratory pump (Ugo Basile, Varese, Italy, 60 breaths/min). Spontaneous breathing was abolished with pancuronium bromide $(2 \mathrm{mg} / \mathrm{kg})$, injected in the posterior penis vein. Airway inflation pressure (AIP), an index of intrathoracic airway caliber, was monitored from a lateral port of the ventilator circuit using a Ugo basile bronchospasm transducer according to the previously described method. ${ }^{16}$

After a 10 -min equilibration period, three successive 1-min aerosol administrations of Ach (50, 100, 200 and $500 \mu \mathrm{g} / \mathrm{ml}$ ) were performed at $10-\mathrm{min}$ intervals with constant monitoring of the airway inflation pressure. The aerosol was generated by a Devilbiss 'Pulmosonic' ultrasonic nebulizer permanently connected in series with the afferent limb of the ventilator circuit. The airway inflation pressure was expressed as percent change over the $100 \%$ obtained by clamping the tracheal cannula at the end of the experiment.

\section{Protocol}

All drugs were prepared extemporaneously in distilled water containing 5\% Arabic gum. Sensitized guinea-pigs were treated orally with either Ro $20-1724(10$ or $30 \mathrm{mg} / \mathrm{kg})$ or milrinone $(30 \mathrm{mg} / \mathrm{kg})$ or zaprinast $(30 \mathrm{mg} / \mathrm{kg}), 24$ and $3 \mathrm{~h}$ before the antigen challenge or saline exposure.

\section{Data analysis}

Results are expressed as means \pm SEM. Statistical differences between the dose-responses to Ach in the groups receiving the various treatment were analyzed by two-way analysis of variance. It was thus possible to examine the whole dose-response curves obtained in these different groups of animals.

\section{Results}

Exposure of anaesthetized guinea-pigs to the successive aerosols of ACh $(50,100,200$ and $500 \mu \mathrm{g} / \mathrm{ml})$ induced a dose-related bronchopulmonary response. When the animals were previously exposed to OA, the dose-response curve to ACh was significantly shifted to the left $(P<0.001)$ (Figs $1-4)$.

When the sensitized guinea-pigs were pretreated with Ro 20-1724 (30 mg/kg), and studied $48 \mathrm{~h}$ after OA, a significant reduction $(P<0.05)$ of the leftward shift of the dose-response curve to ACh was noted (Fig. 1), whereas no effect was observed at the lower dose (10 mg/kg) (Fig. 2).

Administration of milrinone $(30 \mathrm{mg} / \mathrm{kg})$ also elicited a significant reduction $(P<0.05)$ of the leftward shift of the dose-response curve to ACh after OA challenge (Fig. 3), whereas, zaprinast $(30 \mathrm{mg} / \mathrm{kg})$ had no effect (Fig. 4).

\section{Discussion}

The present study demonstrated that the selective PDE4 inhibitor, Ro 20-1724 and the selective PDE3 inhibitor, milrinone, but not the selective PDE5 inhibitor, zaprinast, are able to inhibit the development of airway hyperresponsiveness induced by antigen challenge in sensitized guinea-pigs.

Airway hyperresponsiveness induced by antigen challenge is generally associated in humans and in experimental animals with an influx of inflammatory cells in lung tissue $e^{1,16}$ and the activation of resident 


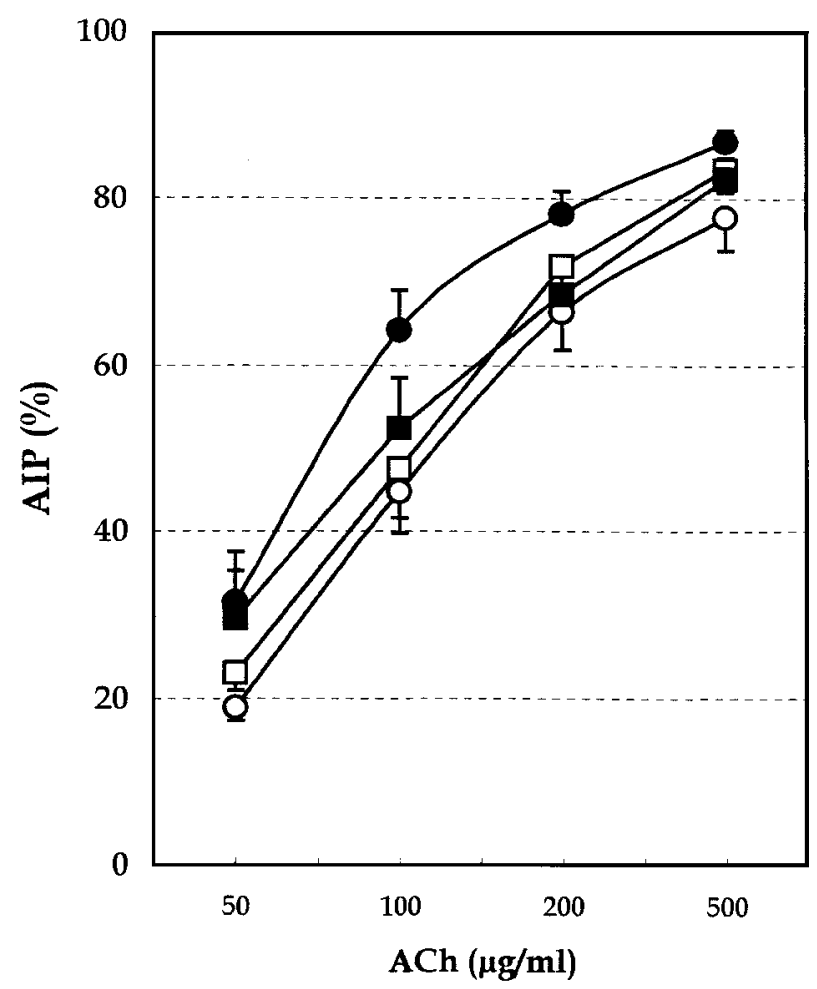

FIG. 1. Influence of Ro 20-1724 $(30 \mathrm{mg} / \mathrm{kg})$ on cumulative dose-response curve for acetylcholine $(50,100,200$ and $500 \mu \mathrm{g} / \mathrm{ml}$ ) in anaesthetized guinea-pigs, $24 \mathrm{~h}$ after ovalbumin challenge (OA). Sensitized guinea-pigs were treated orally with Ro $20-1724(30 \mathrm{mg} / \mathrm{kg}), 24$ and $3 \mathrm{~h}$ before the antigen challenge (OA) or saline exposure (SAL). Symbols represent control with $(\square)$ or without $(\bigcirc)$ Ro 20-1724 and after OA challenge with $(\boldsymbol{\square})$ or without $(\bullet)$ Ro 20-1724 $(n=6-20)$. Significant difference between OA and Ro $20-1724+O A$ is $P<0.05$. No significant difference is noted between SAL+Ro 20-1724 and OA+Ro 20-1724.

pulmonary cells such as alveolar macrophages. ${ }^{9,17,18}$ We have also reported that macrophages recovered in the BAL fluid of either saline-exposed or OA-challenged sensitized guinea-pigs ex hibit a PDE type 3 and a PDE type 4 isoenzyme activity. ${ }^{9}$ It can therefore be suggested that the profile of PDE activities in macrophages may influence the activity of PDE inhibitors. In this regard, we observed that the combination of milrinone and the selective PDE4 inhibitors, rolipram or Ro 20-1724 had a significant inhibitory effect on arachidonate release. ${ }^{9}$ We recently proposed that the reduced activity of alveolar macrophages may be involved in the inhibition of the development of airway hyperresponsiveness by both PDE3 and PDE4 inhibitors and suggest that activation of alveolar macrophages is a key event in the bronchopulmonary alterations that follow antigen challenge.

Such a hypothesis is not consistent with the fact that the development of airway hyperresponsiveness is closely associated with eosinophil influx in airways. We and others have previously demonstrated that PDE4 inhibitors, but not PDE3 inhibitors, are able to reduce the eosinophil recruitment induced either by antigen challenge in sensitized guinea-pigs ${ }^{5,19}$ or administration of chemotactic factor, such as PAF and IL-5 in naive guinea-pig s. ${ }^{5,6}$ This would suggest a dissociation between eosinophil recruitment and the development of airway hyperresponsiveness. This dissociation takes into account the fact that eosinophils do not contain PDE3 isoenzyme, ${ }^{4}$ and then that PDE3 inhibitors are not able to block mediator release from these inflammatory cells. ${ }^{19}$ This hypothesis is also strengthened by the results obtained $w$ ith ae rosol exposure of guinea-pigs to substance P. Indeed, the development of airw ay hyperresponsiveness induced by aerosol administration of substance $P$ is associated with alveolar macrophage activation rather than granulocyte recruitment. ${ }^{2}$ A proposed mechanism for the inhibition of antigen-induced airway hyperresponsiveness by PDE inhibitors is the regulation of cyclic AMP by PDE3 and 4 contributing to the modulation of neuronal sensitivity in the airways and of tachykinin release..$^{20,21}$

It is now generally accepted that selective PDE4 inhibitors are able to reduce airway hyperresponsiveness, and that this effect is associated with anti-

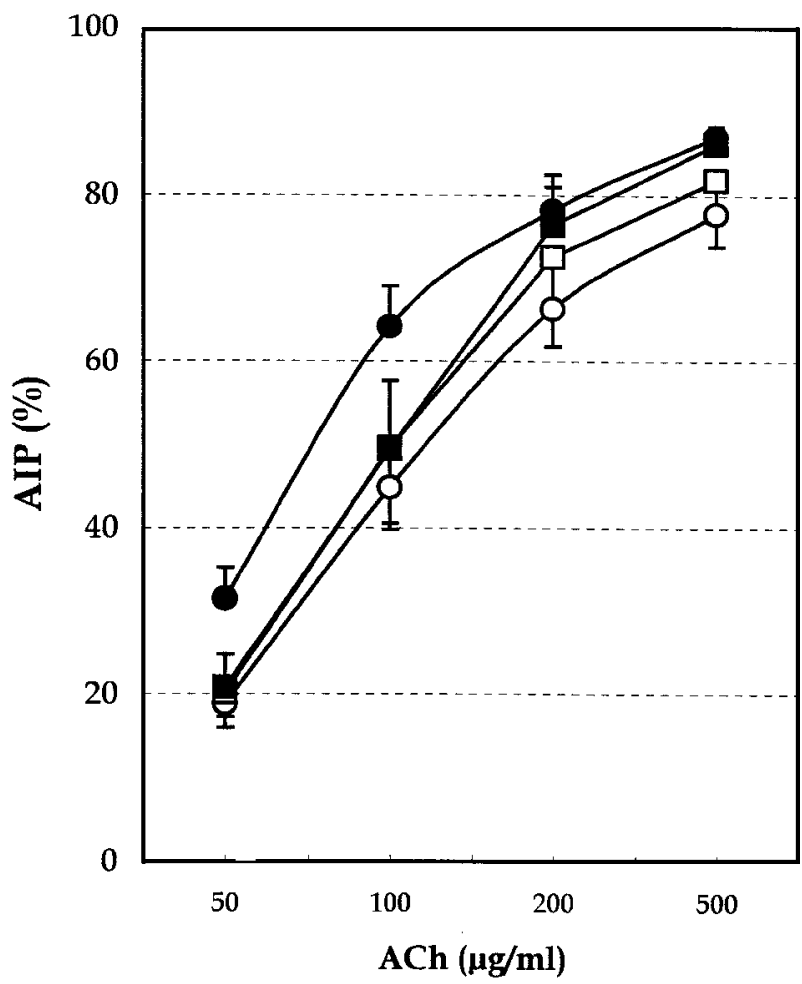

FIG. 2. Influence of Ro $20-1724(10 \mathrm{mg} / \mathrm{kg})$ on cumulative dose-response curve for acetylcholine $(50,100,200$ and $500 \mu \mathrm{g} / \mathrm{ml}$ ) in anaesthetized guinea-pigs, $24 \mathrm{~h}$ after ovalbumin challenge (OA). Sensitized guinea-pigs were treated orally with Ro $20-1724(10 \mathrm{mg} / \mathrm{kg}), 24$ and $3 \mathrm{~h}$ before the antigen challenge (OA) or saline exposure (SAL). Symbols represent control with $(\square)$ or without $(\bigcirc)$ Ro 20-1724 and

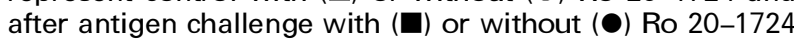
$(n=4-20)$. No significant difference is noted between OA and OA+Ro 20-1724. Significant difference between SAL+Ro 20-1724 and Ro 20-1724+OA is $P<0.05$. 
inflammatory activities. ${ }^{10-12,21}$ However, recent studies have reported the effects of two PDE3 inhibitors. Using cilostazol, Uno and colleagues ${ }^{15}$ have reported an inhibition of LPS-induced bronchial hyperreactivity in guinea-pigs, and Fujimura et $a l^{13}$ a reduced bronchial hyperresponsiveness in asthmatic patients. Finally, Bardin et al. ${ }^{14}$ have reported that the selective PDE3 inhibitor, MKS492, is able to prevent early bronchoconstrictor response in asthma and attenuates late response.

Since PDE3 inhibitors have bronchodilator and bronchoprotective properties, ${ }^{22}$ it can also be suggested that the bronchoprotective effect observed in these latter studies was due to their relaxant activity on smooth muscles. ${ }^{23}$ In the present study, we excluded such a possibility since the bronchopulmonary response induced by acetylcholine was not modified by milrinone in unchallenged animals.

In conclusion, the present study showed that PDE3 (milrinone) and PDE4 inhibitors (Ro 20-1724), but not the PDE5 inhibitor (zaprinast), are able to reduce the development of airway hyperresponsiveness in sensitized guinea-pigs and suggests that this group of

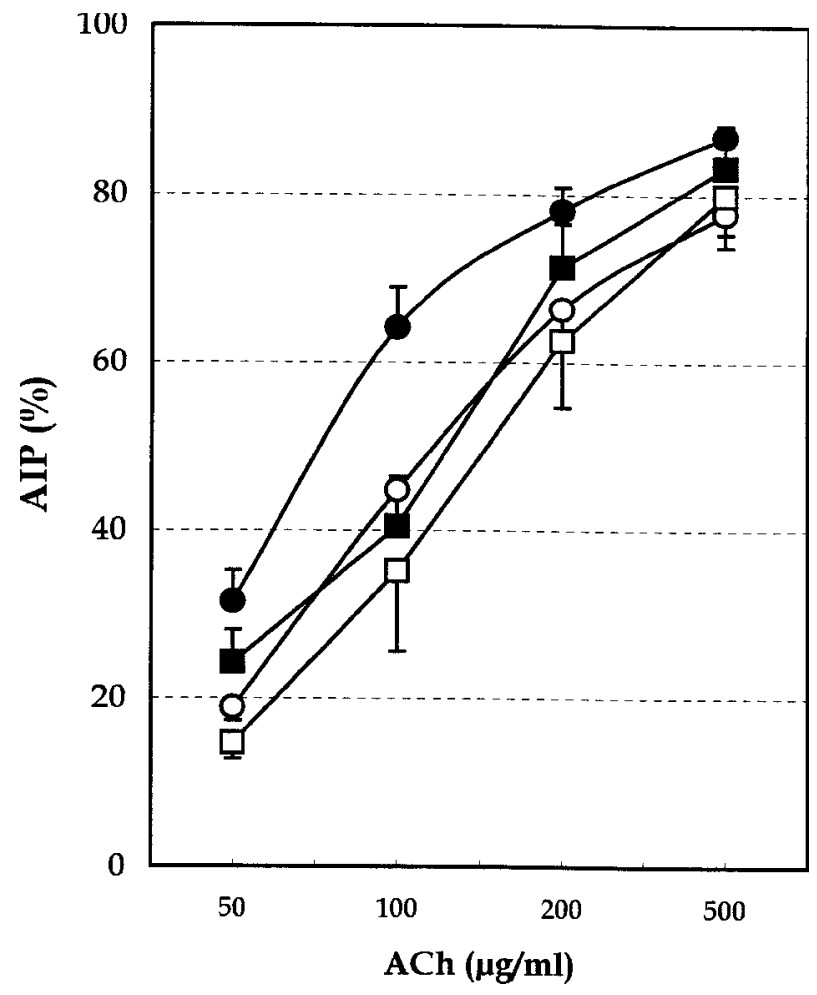

FIG. 3. Influence of milrinone $(30 \mathrm{mg} / \mathrm{kg})$ on cumulative dose-response curve for acetylcholine $(50,100,200$ and $500 \mu \mathrm{g} / \mathrm{ml}$ ) in anaesthetized guinea-pigs, $24 \mathrm{~h}$ after ovalbumin challenge (OA). Sensitized guinea-pigs were treated orally with milrinone $(30 \mathrm{mg} / \mathrm{kg}), 24$ and $3 \mathrm{~h}$ before the antigen challenge (OA) or saline exposure (SAL). Symbols represent control with $(\square)$ or without $(\bigcirc)$ milrinone and after antigen challenge with $(\boldsymbol{\square})$ or without (0) milrinone $(n=6-20)$. Significant difference between OA and milrinone+OA is $P<0.05$. No significant difference is noted between $\mathrm{SAL}+$ milrinone and $\mathrm{OA}+$ milrinone.

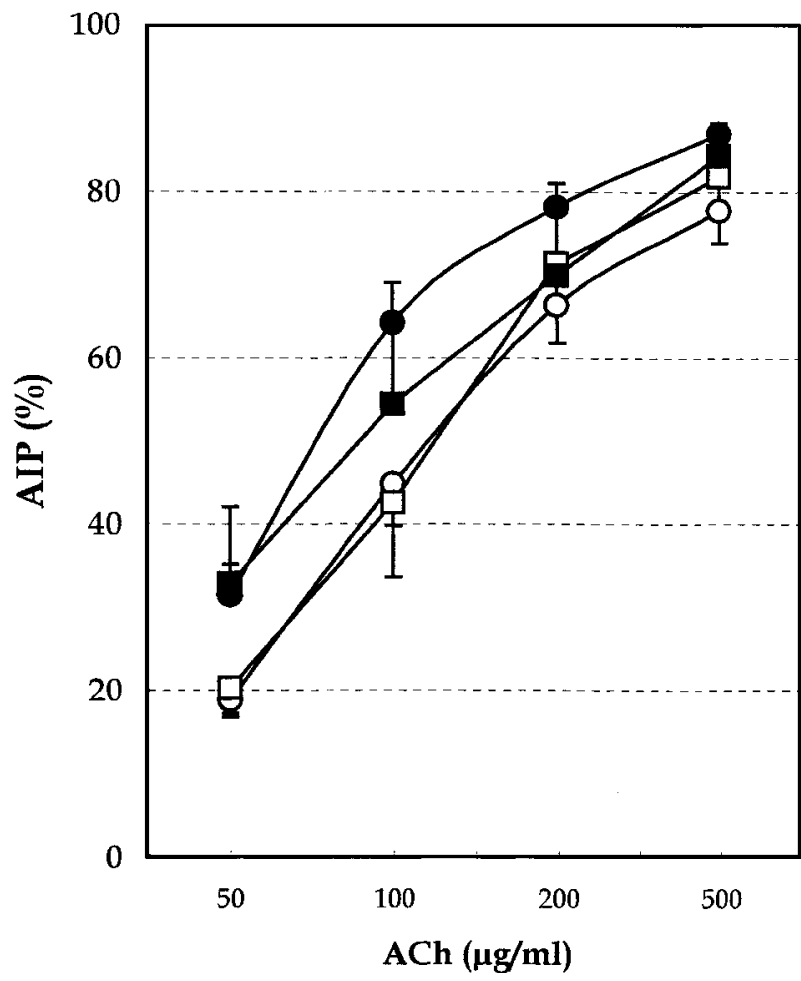

FIG. 4. Influence of zaprinast $(30 \mathrm{mg} / \mathrm{kg})$ on cumulative doseresponse curve for acetylcholine $(50,100,200$ and $500 \mu \mathrm{g} / \mathrm{ml})$ in anaesthetized guinea-pigs, $24 \mathrm{~h}$ after ovalbumin challenge. Sensitized guinea-pigs were treated orally with zaprinast $(30 \mathrm{mg} / \mathrm{kg}), 24$ and $3 \mathrm{~h}$ before the antigen challenge (OA) or saline exposure (SAL). Symbols represent control with ( $\square$ ) or without $(\bigcirc)$ zaprinast and after antigen challenge with ( $\mathbf{\square})$ or without $(\bullet)$ zaprinast $(n=5-20)$. No significant difference is

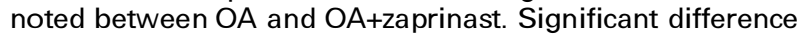
between SAL+Ro 20-1724 and zaprinast+OA is $P<0.01$.

selective compounds may have a role to play in the treatment of asthma.

ACKNOWLEDGEMENTS. The authors thank Guy Bouër for his assistance in preparing the manuscript.

\section{References}

1. Holgate ST, Djukanovic R, Wilson J, Roche W, Roche PH, Howarth PH Inflammatory processes and bronchial hyperresponsiveness. Clin Exp Allergy 1991; 21 (Suppl 1): 30-36.

2. Boichot E, Lagente V, Paubert-Braquet M, Frossard N. Inhaled substance P induces activation of alveolar macrophages and increases airway responses in the guinea-pig. Neuropeptides 1993; 25: 307-313.

3. Teixeira MM, Gristw ood RW, Cooper N, Hellew ell PG. Phosphodieste rase (PDE) 4 inhibitors: anti-inflammatory drugs of the future? Trends Pharmacol Sci 1997; 18: 164-171.

4. Torphy TJ. Phosphodiesterase isozymes. Molecular targets for novel antiasthma agents. Am J Respir Crit Care Med 1998; 157: 351-370.

5. Lagente V, Moodley I, Perrin S, Mottin G, Junien JL. Effects of isozymeselective phosphodiesterase inhibitors on eosinophil infiltration in the guinea-pig lung. Eur J Pharmacol 1994; 255: 253-256.

6. Lagente V, Pruniaux MP, Junien JL, Moodley I. Modulation of cytokineinduced eosinophil infiltration by phosphodiesterase inhibitors. $\mathrm{Am} \mathrm{J}$ Respir Crit Care Med 1995; 151: 1720-1724.

7. Beavo JA, Conti M, Heaslip RJ. Multiple cyclic nucleotide phosphodieste rases. Mol Pharmacol 1994; 46: 399-405.

8. Gantner F, Kupferschmidt R, Schudt C, Wendel A, Hatzelmann A. In vitro differentiation of human monocytes to macrophages: change of PDE profile and its relationship to suppression of tumor necrosis factor-a release by PDE inhibitors. Br J Pharma col 1997; 121: 221-231.

9. Germain N, Bertin B, Legendre A, Martin B, Lagente V, Payne A., Boichot E. Selective phosphodiesterase inhibitors modulate the activity of alveolar macrophages from sensitized guinea-pigs. Eur Respir J 1998; 12: $1334-1339$. 
10. Howell RE, Sickels BD, Woeppel SL. Pulmonary antiallergic and bronchodilator effects of isozyme-selective phosphodiesterase inhibitors in guinea-pigs. J Pharmacol Exp Ther 1993; 264: 609-615.

11. Ortiz JL, Valles JM, Marti-Cabrera M, Cortijo J, Morcillo EJ. Effects of selective phosphodiesterase inhibitors on platelet-activating factor-and antigen-induced airway hyperreactivity, eosinophil accumulation and microvascular leakage in guinea-pigs. Naunyn Schmiedebergs Arch Pharmacol 1996; 353: 200-206.

12. Danahay H, Broadley KJ. Effects of inhibitors of phosphodieterase, on antigen-induced bronchial hyperreactivity in conscious sensitized guineapigs and airway leukocyte infiltration. Br J Pharmacol 1997; 120: 289-297.

13. Fujimura M, Kamio Y, Myou S, Hashimoto T, Matsuda T. Effect of phosphodiesterase 3 inhibitor, cilostazol, on bronchial hyperresponsiveness in elderly patients with asthma. Int Arch Allergy Imm unol 1997; 114: 379-384.

14. Bardin PG, Dorward MA, Lampe FC, Franke B, Holgate ST. Effect of selective phosphodiesterase 3 inhibition on the early and late asthmatic responses to inhaled allergen. Br J Clin Pharmacol 1998; 45: 387-391.

15. Uno T, Tanaka H, Nagai H. Effects of isoenzyme selective phosphodiesterase inhibitors on bacterial lipopolysaccharide-induced bronchial hyperre activity in guinea-pigs. Gen Pharm acol 1998; 30: 167-173.

16. Boichot E, Lagente V, Carre C, Waltmann P, Mencia-Hue rta JM, Braquet P. Bronchial hyperresponsiveness and cellular infiltration in the lung of guinea-pigs sensitized and challenged by aerosol. Clin Exp Allergy 1991; 21: 67-76.

17. Tonnel AB, Gosset P, Joseph M, Fournier E, Capron A. Stimulation of alveolar macrophages in asthmatic patients after local provocation tests. Lancet 1983 ; i: $1406-1408$.
18. Lagente V, Boichot E, Chadli S, Dugas B, Mencia-Huerta JM, Braquet P. Effect of the platelet-activating factor antagonist, BN 50730, on the increased production of superoxide anions by alveolar macrophages from antigenexposed sensitized guinea-pigs. Fund Clin Pharmacol 1991; 5: 426.

19. Banner KH, Page CP. Theophylline and selective phosphodiesterase inhibitors as anti-inflammatory drugs in the treatment of bronchial asthma. Eur Respir J 1995; 8: 896-1000.

20. Spina D, Harrison S, Page CP. Regulation by phosphodiesterase isoenzymes of non-adrenergic non-cholinergic contraction in guinea-pig isolated main bronchus. Br J Pharmacol 1995; 116: 2334-2340

21. Holbrook M, Gozzard N, James T, Higgs G, Hughes B. Inhibition of bronchospasm and ozone-induced airway hyperresponsiveness in the guinea-pig by CDP 840 , a novel phosphodiesterase type 4 inhibitor. $\mathrm{Br}$ I Pharmacol 1996; 118: $1192-1200$.

22. Rabe KF, Tenor H, Dent G, Schudt C, Liebig S, Magnussen $H$. Phosphodiesterase isozymes modulating inherent tone in human airways: identification and characterization. Am J Physiol 1993; 264: L458-L464.

23. Planquois JM, Ruffin-Morin Y, Lagente V, Payne AN and Dahl SG. Salbutamol potentiates the relaxant effects of selective phosphodiesterase inhibitors on guinea-pig isolated trachea. Fund Clin Pharmacol 1996; 10: 356-367.

\section{Received 11 February 1999;}

accepted in revised form 31 March 1999 


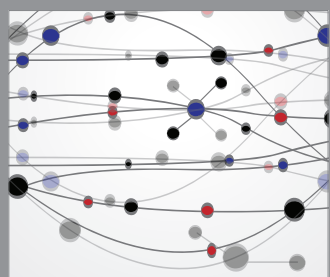

The Scientific World Journal
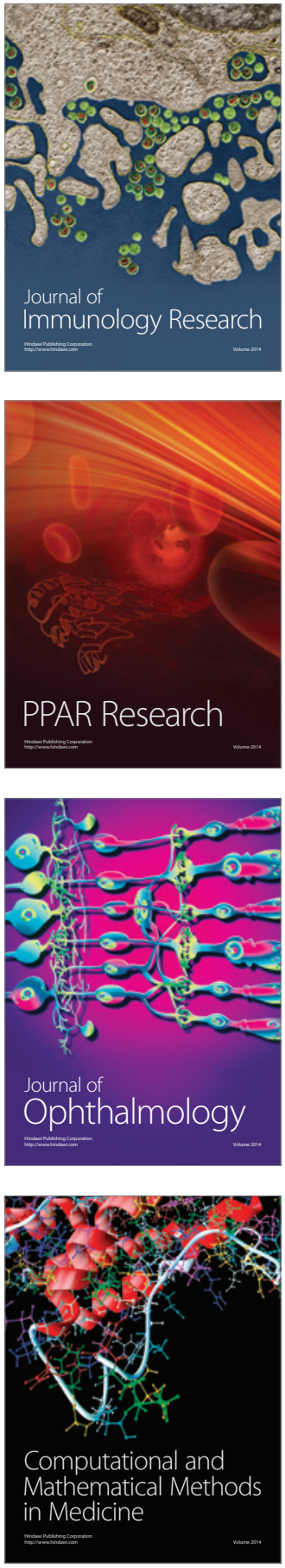

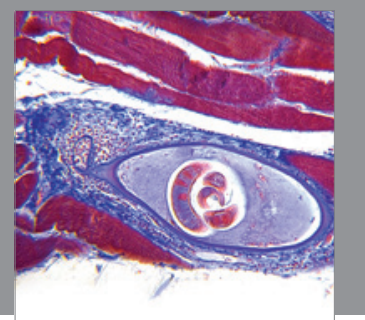

Gastroenterology

Research and Practice
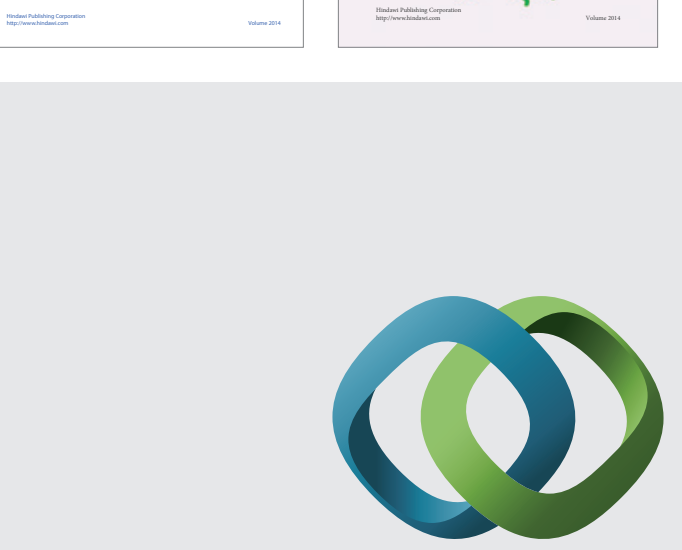

\section{Hindawi}

Submit your manuscripts at

http://www.hindawi.com
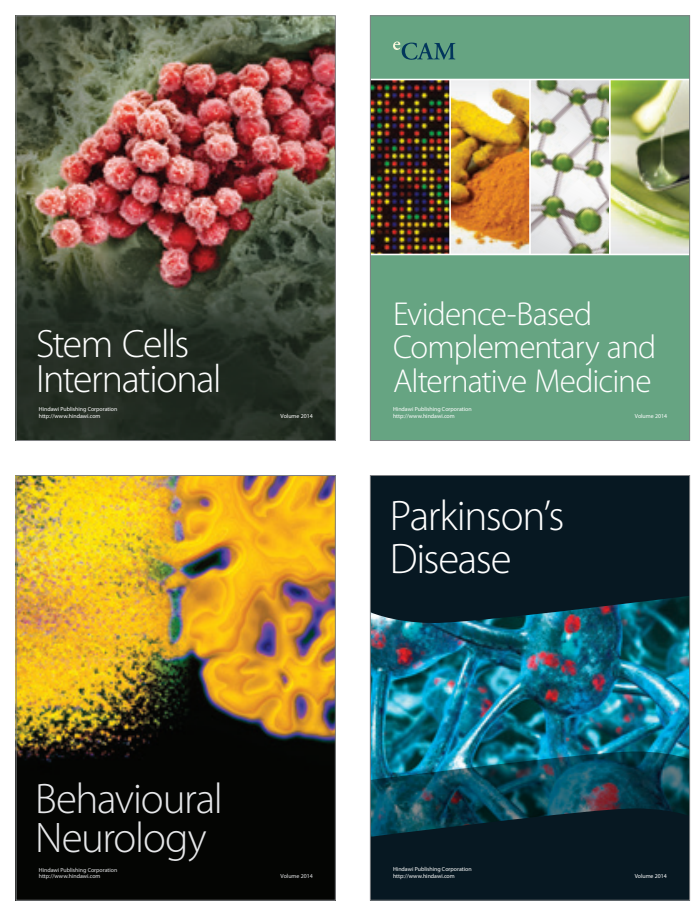

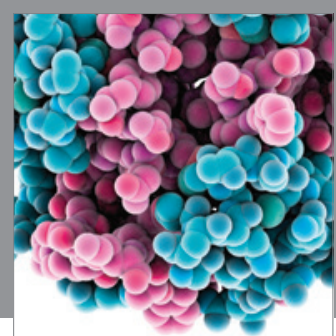

Journal of
Diabetes Research

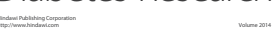

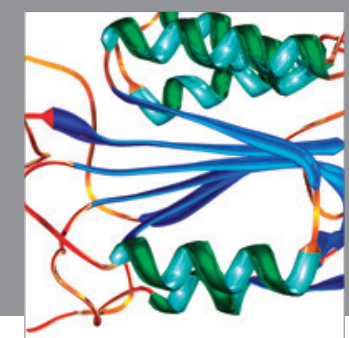

Disease Markers
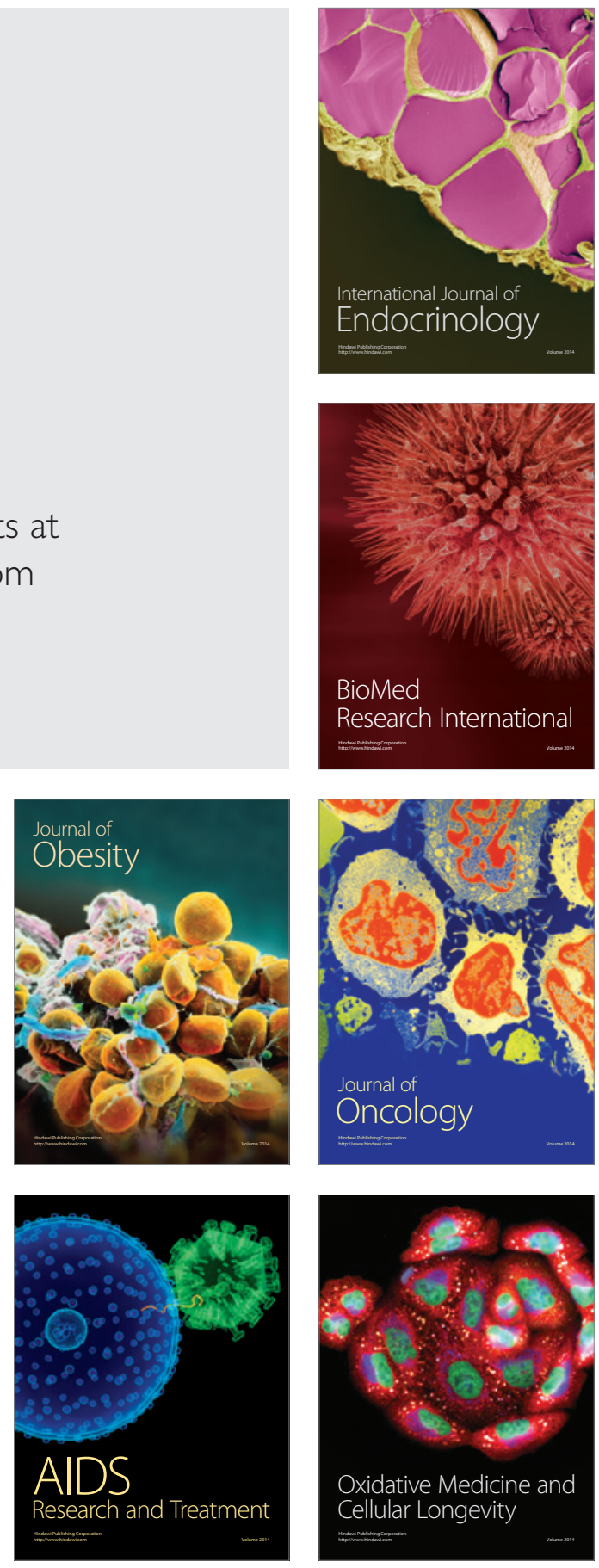